\title{
Curcumin promotes the proliferation, invasion of neural stem cells and formation of neurospheres via activating SDF-1/CXCR4 axis
}

\author{
Yahui Chen ${ }^{1}$, Fangfang Yuan ${ }^{1}$, Jixia Lin ${ }^{1}$, Xin Zhang ${ }^{2}$, Jing Luo ${ }^{1}$, Lifa Huang ${ }^{2}$ \\ ${ }^{1}$ Ningbo No. 6 Hospital, China, ${ }^{2}$ the First Affiliated Hospital of Zhejiang University of Traditional Chinese Medicine, China
}

\begin{abstract}
Curcumin is an active ingredient isolated from the rhizomes of Curcuma longa Linn with remarkably non-toxic bioavailability. This is an in vitro study. In this study, we explored the effects of curcumin on the proliferation, migration and neurogenesis of neural stem cells (NSCS). Primary NSCS were isolated from embryonic day 14 rats and then treated with curcumin and/or stromal derived factor-1 (SDF-1). NSCS showed an SDF-1-dependent proliferation and migration. Further results showed that curcumin and SDF-1 both promoted NSCS proliferation, migration and the formation of neurospheres. In addition, Curcumin up-regulated the expression of SDF-1 and promoted the formation of SDF-1/CXCR4 complex in NSCS. The western blot results showed that the phosphorylation levels of ERK, JNK, MAPK, NF- $K B$ and Akt were up-regulated by curcumin. In contrast, the administration of CXCR4 inhibitor AMD3100 could offset the effect of curcumin. These results suggested that curcumin promoted the NSCs proliferation, migration and formation of neurospheres via SDF-1/CXCR4 in NSCS.
\end{abstract}

Key words: curcumin, stromal derived factor-1, neural stem cells.

\section{Introduction}

Neural stem cells (NSCs) are precursor cells that produce neurons and strand cells, have the potential to differentiate into neurons, astrocytes, and oligodendrocytes, and have the potential to be self-renewing and sufficient to provide a large number of neural tissue cells [5]. Under normal conditions, NSCs remain dormant and can only be activated when stimulated by certain conditions. During cerebral ischemia, NSCs in the hippocampus, cerebral cortex and other regions begin to proliferate, further migrate, differentiate into neurons, establish new neural connections, replace damaged nerves and promote nerve repair in the ischemic region [21]. This suggests that endogenous NSCs have the ability to repair ischemic brain damage. However, the number of NSCs obtained through the activation of endogenous NSCs is small, and the activating factor that regulates the migration and differentiation of NSCs is insufficient, resulting in the failure to repair the neurological deficit itself [7]. Therefore, it is important to find a drug that effectively promotes the proliferation, invasion and neurogenesis of NSCs.

The aggregation or overexpression of stromal derived factor-1 (SDF-1) in NSCs enhances the migration of NSCs to injury regions and maintains the stemness signature of NSCs $[9,11]$. There is evidence showing that the chemoattractant SDF-1 is capable of providing a protective effect against cerebral isch- 
emia-reperfusion injury-induced neuron damage by attracting chemokine (CXC motif) receptor 4 (CXCR4) expression in NSCs and promoting NSCs maturation [11]. Many studies have shown the neuronal protection, regeneration, and NSCs migration ability of the SDF-1/CXCR4 axis overexpression [3,27].

Curcumin (diferuloylmethane) is the active ingredient isolated from the rhizomes of the traditional herbal remedy Curcuma longa Linn (turmeric). Because of its remarkably non-toxic bioavailability to reduce cognitive deficits, scavenge free radicals and inhibit inflammation, curcumin has traditionally been used for the treatment of diseases associated with aging, neurodegeneration $[6,8,20,24]$. Curcumin has been reported to be capable of neuroprotective ability by preventing the neuronal apoptosis [14,29]. In addition, curcumin could promote the proliferation of embryonic neural progenitor cells (NPCs) and NSCs, neurogenesis in the hippocampus of adult rats and reducing free radicals. Thus, it has a good effect on cerebral injury, stroke or even Alzheimer's disease $[2,13,14,17,29]$. However, the mechanism of curcumin on the neurogenesis of NSCs has been not clarified. In this study, we investigated the effects of curcumin on the proliferation, invasion and neurogenesis of NSCS, and further revealed that curcumin acts on the neurogenesis of NSCs mainly through SDF-1/CXCR4 axis.

\section{Material and methods}

\section{Neural stem cells isolation, passage and culture conditions}

Primary NSCs were isolated from the cortices of embryonic day 14 Sprague-Dawley rats as previously described [30]. In brief, rats were anesthetized using chloral hydrate $(10 \%, 3 \mathrm{ml} / \mathrm{kg}$ body weight; SigmaAldrich; Merck KGaA, Darmstadt, Germany), cerebral cortexes were dissected and dissociated into single-cell suspensions using surgical scissors. All animal experiments conformed to the guidelines of the Animal Ethics Committee of Zhejiang Chinese Medicine University Laboratory Animal Research Center.

Single cells were transferred into completed DMEM/F12 medium (Sigma-Aldrich; Merck KGaA) supplemented with penicillin/streptomycin $(100 \mathrm{U} / \mathrm{ml})$, B27 (2\%), epidermal growth factor (EGF, $10 \mathrm{ng} / \mathrm{ml}$ ) or basic fibroblast growth factor (bFGF, $10 \mathrm{ng} / \mathrm{ml}$; PeproTech, Rocky Hill, TX, USA) at $37^{\circ} \mathrm{C}$ with $5 \% \mathrm{CO}_{2}$. NSCs were passaged with the density of $1.0 \times 10^{4}$ cells $/ \mathrm{cm}^{2}$. The $2^{\text {nd }}$ to $4^{\text {th }}$ passage NSCs were used in all experiments. For the formation of the neurosphere, the $2^{\text {nd }}$ passage NSCs were treated under the above conditions with half replaced medium every two days for 14 days. The number of neurospheres in each condition was counted. For other cellular experiments, cell cultures were half replaced with fresh DMEM/F12 medium supplemented with above factors every two days.

\section{Cell treatments}

For curcumin treatment, NSCs of the $2^{\text {nd }}$ to $4^{\text {th }}$ passage were placed into 96 -well plates $\left(1.0 \times 10^{4}\right.$ cells/well) and treated with $1 \mu \mathrm{M}$ curcumin (SigmaAldrich 08511, HPLC $\geq 98.0 \%$; Merck KGaA) [1,19] for $48 \mathrm{~h}$. For the inhibition of CXCR4, $10 \mu \mathrm{M}$ AMD3100 (Sigma-Aldrich; Merck KGaA) [22] was supplemented into the cell cultures and incubated for another $8 \mathrm{~h}$. For the treatment with SDF-1, the $2^{\text {nd }}$ to $4^{\text {th }}$ passage NSCs were placed into 96-well plates $\left(1.0 \times 10^{4}\right.$ cells $/$ well) and treated with SDF-1 at the final concentrations of $0,5,25$, and $50 \mathrm{ng} / \mathrm{ml}$ for 24,48 and $72 \mathrm{~h}$. All cells were maintained at $37^{\circ} \mathrm{C}$ in $5 \% \mathrm{CO}_{2}$. Each experiment was performed in 3 replications.

\section{Cell proliferation assay}

Cell proliferation was detected using the MTT assay (Sigma-Aldrich; Merck KGaA). In brief, NSCs were seeded into 96-well plates with a final density of $1.0 \times 10^{5}$ cells/well for $48 \mathrm{~h}$ for confluence. Cell viability at 24, 48 and $72 \mathrm{~h}$ post treatments were detected in MTT solutions (RiboBio, Guangzhou, China) according to the manufacturer's instruction. The optical density (OD450) was determined using a microplate spectrophotometer (Thermo Fisher Scientific, Waltham, MA, USA). Each experiment was performed in triplicate.

\section{Transwell assay}

The chemotactic response of NSCs to the chemoattractant SDF-1 was detected using the transwell assay. In brief, $1.0 \times 10^{5}$ cells were seeded into the upper chamber coated with Matrigel (BD Biosciences, San Diego, CA, USA) and incubated in completed DMEM/F12 supplemented with other factors as listed above. The lower chambers were filled with completed DMEM/F12 supplemented with SDF-1 $(0,5,25$, and $50 \mathrm{ng} / \mathrm{ml})$ and other factors for 24,48 and $72 \mathrm{~h}$. After removing cells on the upper surface, 
transwell filters were fixed with paraformaldehyde and stained with crystal violet (RiboBio, Guangzhou, China). The experiment was performed in triplicate. The invaded cells were captured using a Motic inverted microscope (AE30; Motic, Hong-Kong, China) and the number of average invaded cells of 5 randomly selected fields was calculated.

\section{Immunofluorescence assay}

Immunofluorescence assay for the neurosphere was performed at 14 days post the formation of neurosphere. NSCs were fixed and the immunocytochemically staining analysis for glial fibrillary acidic protein (GFAP, 1 : 200; Boster Biotechnology, Wuhan, China) and Nestin (1:50; eBiosciences, San Diego, CA, USA) was performed with primary incubation at $4^{\circ} \mathrm{C}$ overnight. The goat-anti-rabbit immunoglobulin $G$ (IgG, $1: 500$, Boster Biotechnology) secondary antibody was used for further incubation. DAPI staining was performed for nuclear staining in dark at $4^{\circ} \mathrm{C}$ for $10 \mathrm{~min}$. Immunofluorescence assay for the single cells was performed at 7 days post the differentiation culture. Double-immunostaining was performed for the SDF-1 (1:200; Abcam, Cambridge, UK) and CXCR4 (1 : 150; Abcam) antibodies in NSCs single cells. A LSM710 laser scanning confocal microscope (Zeiss, Thornwood, NY, USA) was used for capturing the images of immunofluorescence assay.

\section{Western blot analysis}

Protein samples were isolated from the NSCS under different treatments using RIPA lysis buffer (Beyotime Institute of Biotechnology, Haimen, China). A protein quantification kit (Thermo Fisher Scientific) was used for the protein quantification. $40 \mu \mathrm{g}$ of samples from each experiment was separated onto the SDS-PAGE (10\%; Shanghai Sangon Biotechnology Co., Ltd., Shanghai, China) at $120 \mathrm{~V}$ for $1.5 \mathrm{~h}$, followed by transferring onto the PVDF membranes (Millipore, Bedford, MA, USA) at $300 \mathrm{~mA}$ for $15 \mathrm{~min}-2 \mathrm{~h}$. PVDF membranes carrying protein fragments were blocked using 5\% skim milk powder (RiboBio), incubated in solutions containing primary antibodies against total (t)/phosphorylated (p)-NF- $\kappa B$ (1 : 1000; Boster Biotechnology), t/p-Akt (1:1000; Boster Biotechnology), t/p-JNK (1:1000; eBiosciences), t/p-MAPK (1 : 1500; eBiosciences), t/p-ERK1/2 (1: 1000; Boster Biotechnology), CXCR4 (1 : 1500; eBiosciences) and $\beta$-actin $\left(1: 2000 ;\right.$ Abcam) at $4^{\circ} \mathrm{C}$ overnight. HRP Goat anti-rab- bit/mouse IgG secondary antibody ( $1: 20,000$; Boster Biotechnology) was used for the further incubation at $37^{\circ} \mathrm{C}$ for $1 \mathrm{~h}$. A Bio-5000 plate reader (MicroTek, USA) equipped with Image-Pro Plus 6.0 software were used for band intensity analysis.

\section{Statistical analysis}

At least three repeated experiments have been performed. The data were processed by SPSS 25.0 statistical software. Two-tailed $t$-test and one-way ANOVA was applied in the analysis, in which ${ }^{*} p<0.05$ and ${ }^{* \star} p<0.01$.

\section{Results \\ SDF-1 promotes NSCs proliferation and induces chemotaxis}

We firstly detected the effect of chemokine SDF-1 on NSCs proliferation. MTT assay showed that the administration of SDF-1 promoted the proliferation of NSCs in a time- and dose-dependent manner (Fig. 1A). The viabilities of NSCs incubated with 5 to $50 \mathrm{ng} / \mathrm{ml} \mathrm{SDF}-1$ were significantly higher than those of blank NSCs $(p<0.01)$, and the effect of promotion increased with the concentration of SDF-1. The transwell assay with SDF-1 implied as much, suggesting that the chemokine SDF-1 is a chemoattractant for NSCs (Fig. 1B). The effect of chemotaxis increased with the time and concentration of SDF-1. Accordingly, we selected the $50 \mathrm{ng} / \mathrm{ml}$ concentration for further cellular experiments.

\section{Co-location of the CXCR4 and SDF-1 in NSCs}

We carried out co-immunofluorescence assay of CXCR4 and SDF- 1 on NSCs and confirmed that CXCR4 and SDF-1 were co-expressed in NSCs (Fig. 2). Both CXCR4 and SDF-1 expressions were simultaneously enhanced by curcumin or/and SDF-1. AMD3100 is a specific antagonist to the SDF-1/CXCR4 axis [18]. The administration of AMD3100 eliminated curcumin and SDF-1 enhanced expression of CXCR4 and SDF-1 in NSCs. These data suggested the formation of SDF-1 in complex with CXCR4 in NSCs.

\section{Curcumin and SDF-1 promote astrocyte differentiation}

It has been reported that nestin is a marker of multipotent NSCs and GFAP is a class of III interme- 
A

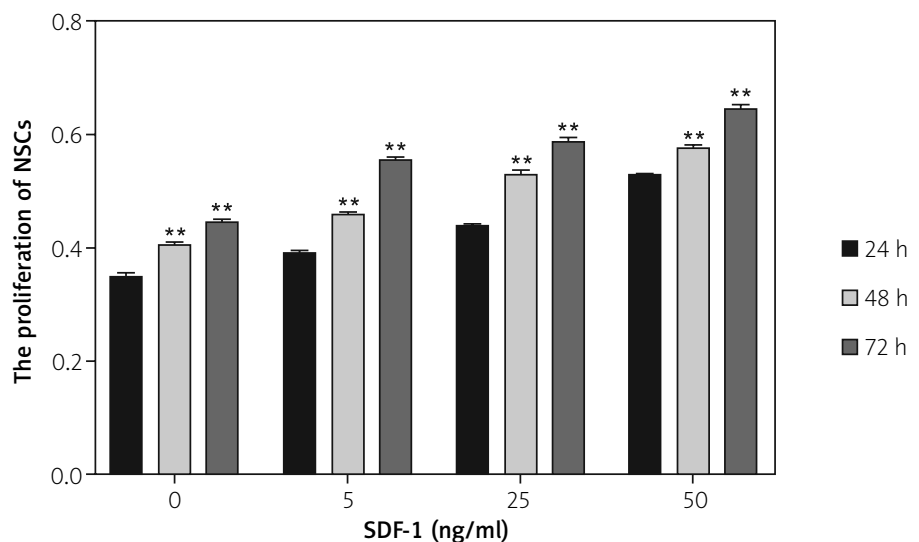

B

$0 \mathrm{ng} / \mathrm{ml}$

$5 \mathrm{ng} / \mathrm{ml}$

$25 \mathrm{ng} / \mathrm{ml}$

$50 \mathrm{ng} / \mathrm{ml}$
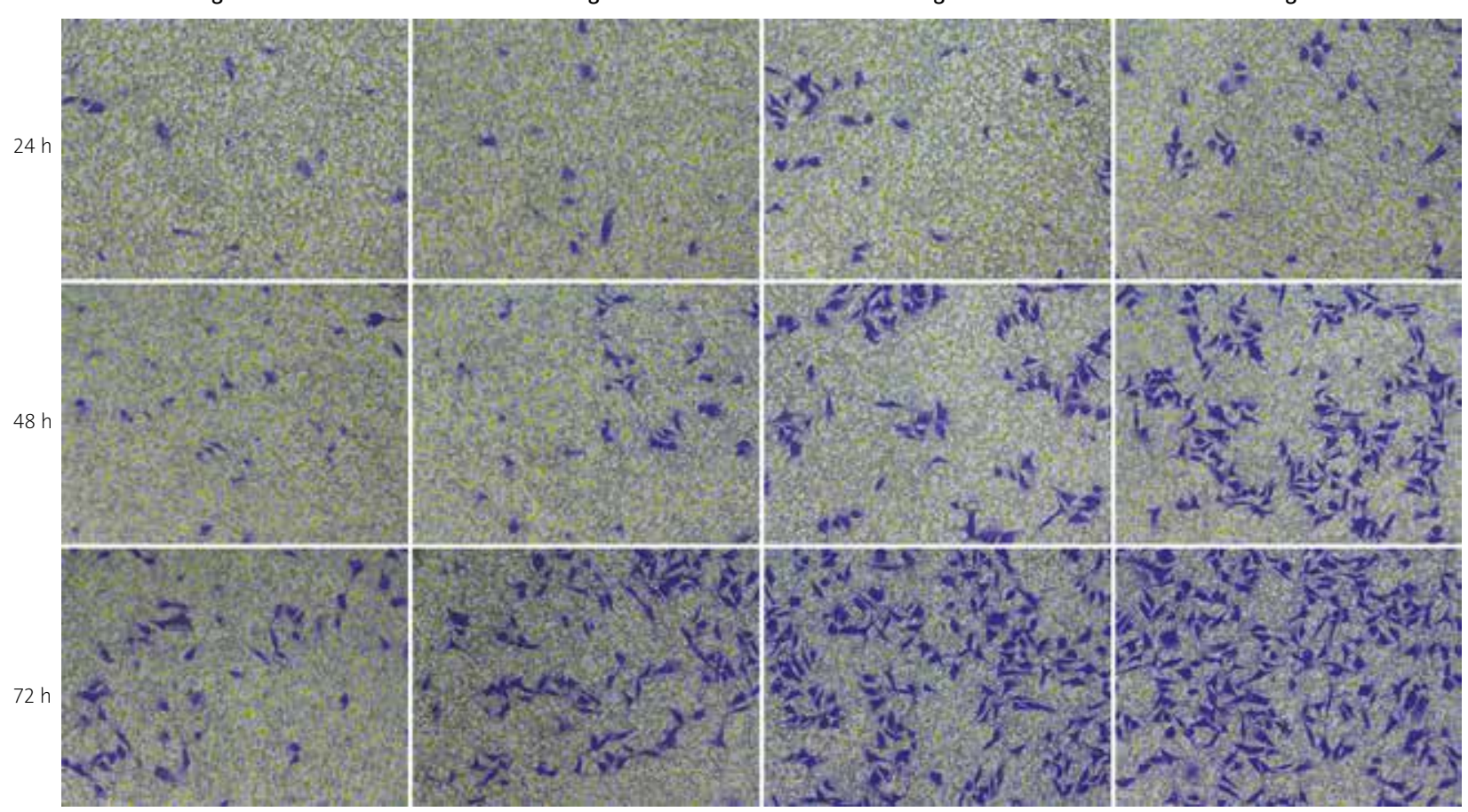

Fig. 1. Cell proliferation and chemotaxis assay. A) The cell proliferation analysis by MTT assay. B) The SDF-1 chemotaxis in NSCS. The error bars are presented as mean \pm SD, ${ }^{* *} p<0.01$.

diate filament protein that is highly expressed in the central nervous system (CNS) [15,32]. Immunofluorescence assay revealed that the expression of GFAP in NSCs showed a similar trend with cell proliferation and invasion assay (Fig. 3). GFAP expression was enhanced by curcumin or/and SDF-1, but receded by AMD3100. These data revealed that CXCR4 may be involved in regulation of the proliferation of NSCs mediated by curcumin and SDF-1. However, nestin expression exhibited an inverse trend to GFAP, as receded by curcumin or/and SDF-1. This result showed that the administration of curcumin or/and SDF-1 promoted the differentiation of NSCS into astrocytes.

\section{Curcumin and SDF-1 promote NSCs cell proliferation via activation of CXCR4}

To investigate the association of CXCR4 with curcumin and SDF-1-mediated NSCs proliferation, we then treated NSCs cell with multiple factors. We observed that the curcumin or/and SDF-1 obviously promoted NSCs cell proliferation $(p<0.01$, Fig. $4 A$ ), forma- 


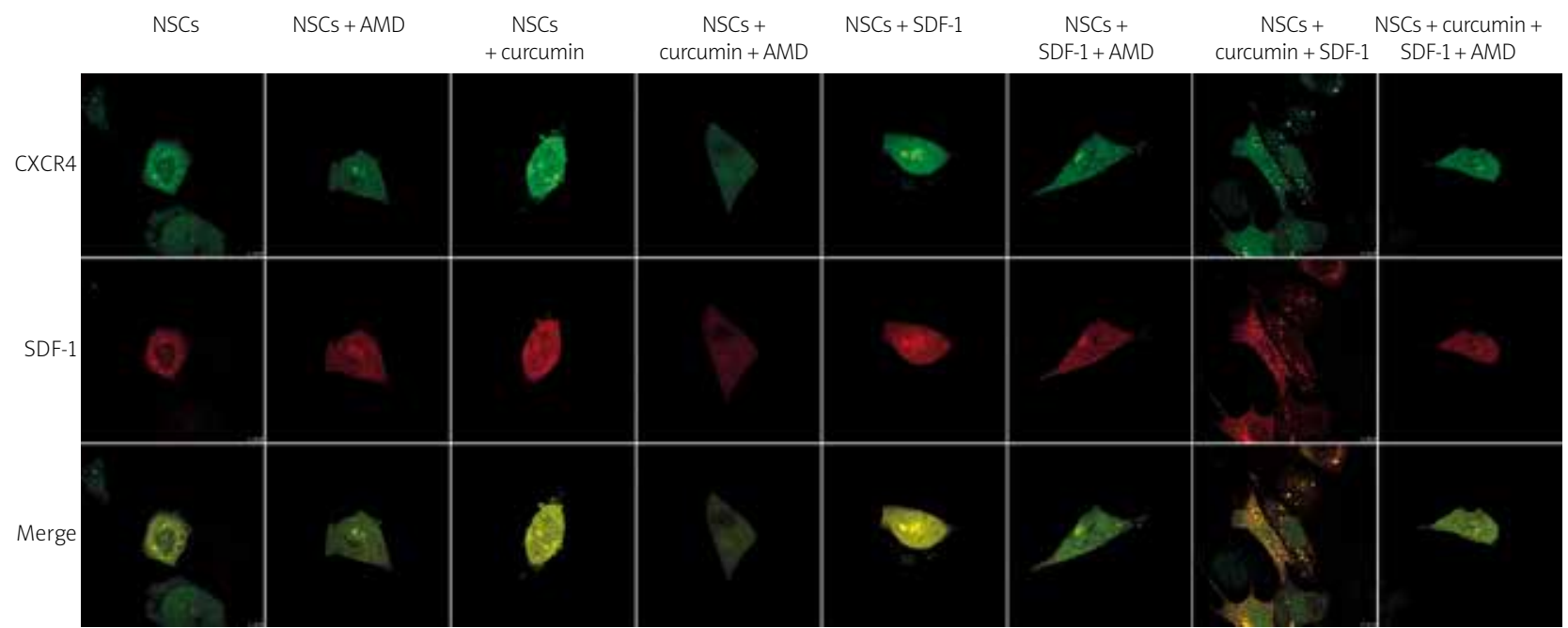

Fig. 2. Co-expression of SDF-1 and CXCR4 in NSCs. Green and red colour indicates CXCR4 and SDF-1 expression, respectively. SDF-1 and CXCR4 were simultaneously enhanced by curcumin or/and SDF-1.

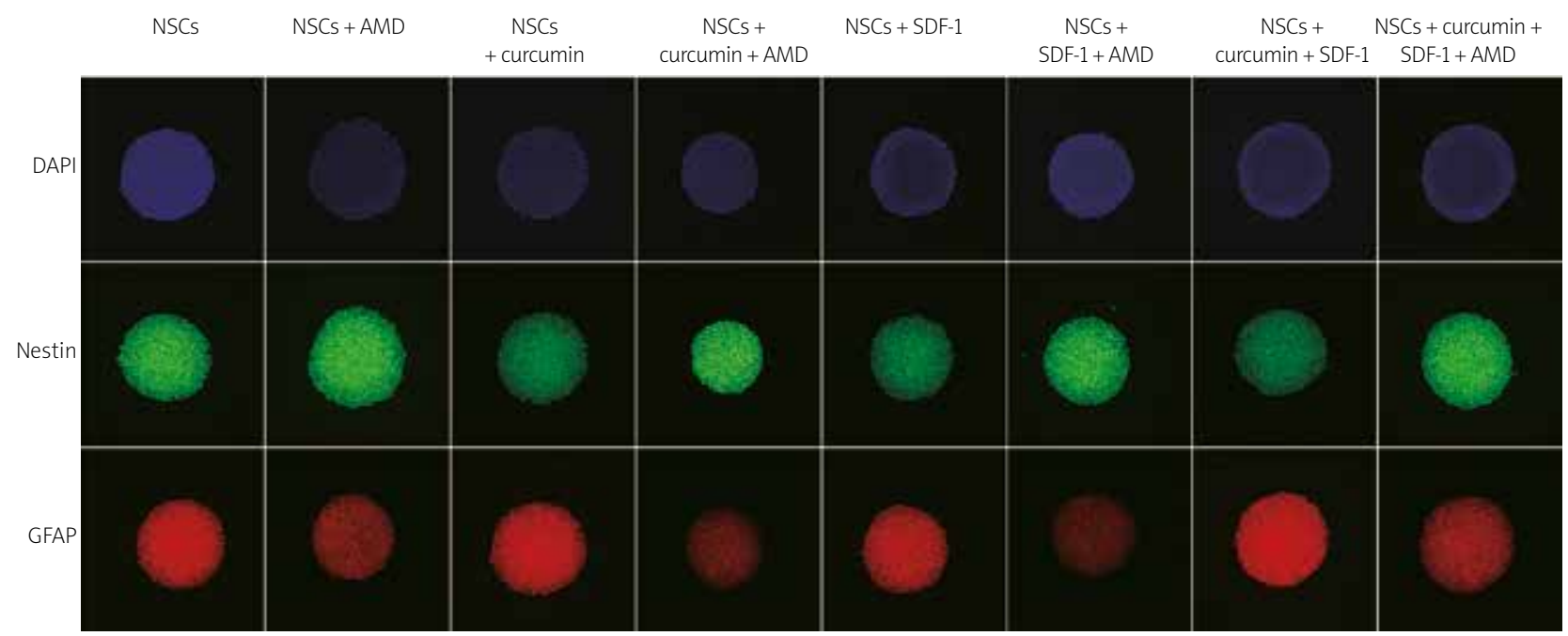

Fig. 3. Immunofluorescence assay for NSCs. Green and red colour indicates nestin and GFAP expression, respectively. The nuclei are stained with DAPI (blue).

tion of neurospheres ( $p<0.01$, Fig. 4B), and invasion ( $p<0.01$, Fig. 4C). However, the blocking of CXCR4 activation using AMD3100 eliminated the above changes induced by curcumin and chemokine SDF-1 to comparable levels with control cells (NSCs, $p>0.05$, Fig. 4).

\section{Curcumin activates NF- $\mathrm{B}$, Akt, JNK, MAPK and ERK signalling pathway through SDF-1/CXCR4 axis}

Since the SDF-1/CXCR4 complex could promote the NSCs proliferation, invasion and the formation of neurospheres, we examined the expression of the cell proliferation-related signalling pathway. The results of western blot showed that the expression of CXCR4 and the phosphorylation levels of NF-KB, Akt, JNK, MAPK, and ERK1/2 were significantly up-regulated by the administration of curcumin and SDF-1 in NSCs (Fig. 5). The inhibition of CXCR4 by AMD3100 administration reversed curcumin or/and SDF-1-mediated changes in NSCs. The results suggested that curcumin may regulate NF- $\kappa B$, Akt, JNK, MAPK and ERK signal pathways to induce the proliferation of NSCs through the SDF-1/CXCR4 axis.

\section{Discussion}

Our present study demonstrated that the curcumin treatments promoted the proliferation, migration and differentiation of NSCs via up-regulating SDF-1/ 
A

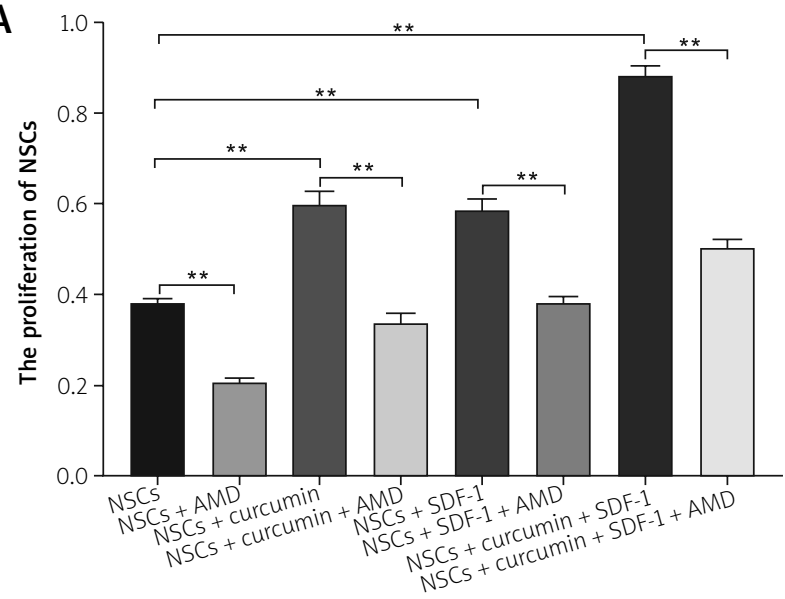

C

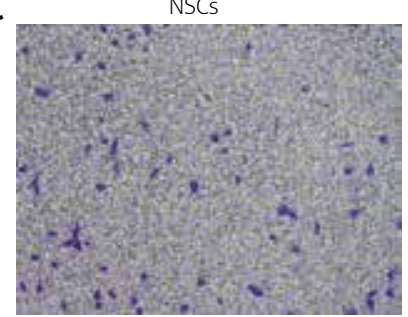

$\mathrm{NSCS}+\mathrm{SDF}-1$

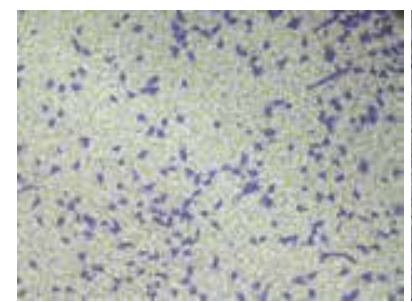

$\mathrm{NSCS}+\mathrm{AMD}$

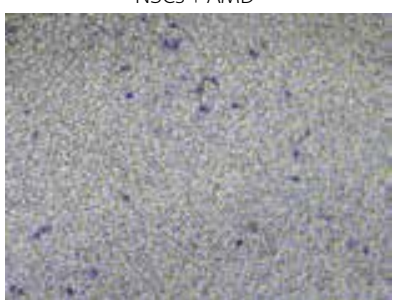

$\mathrm{NSCS}+\mathrm{SDF}-1+\mathrm{AMD}$

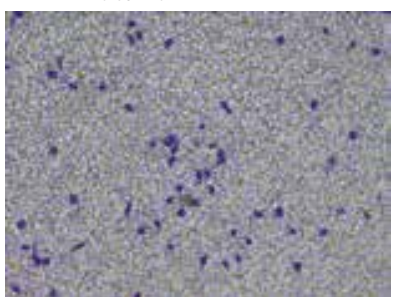

B

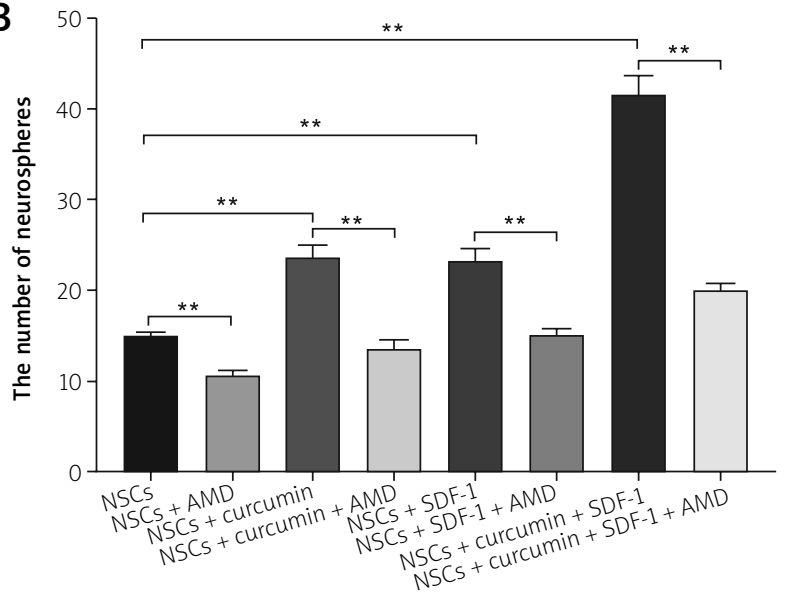

NSCs + curcumin

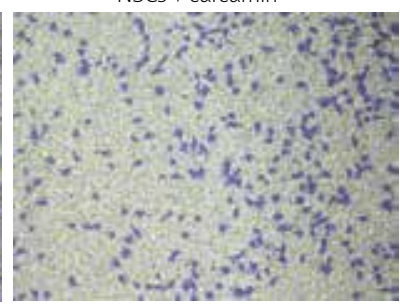

$\mathrm{NSCS}+$ curcumin + SDF-1

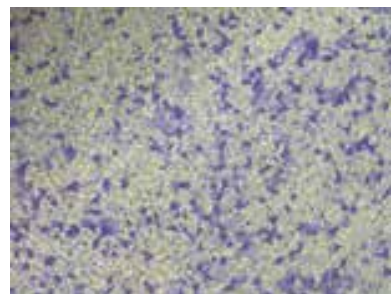

NSCS + curcumin + AMD

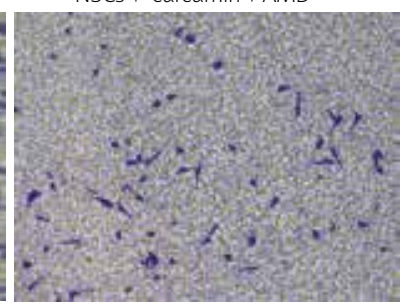

NSCS + curcumin + SDF-1 + AMD

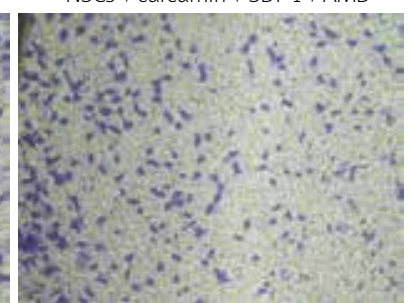

Fig. 4. Effect of curcumin and SDF-1 on NSCs cell proliferation, neurosphere formation and invasion. A) The cell proliferation analysis by MTT assay. B) The formation of NSCs neurospheres. C) The in vitro transwell invasion assay. At least three repeats were carried out, and the mean $\pm S D$ is presented, ${ }^{* *} p<0.01$.

CXCR4 axis. Our results showed that SDF-1 single treatment promoted the NSCs proliferation, invasion and the formation of neurospheres via the activation of CXCR4, JNK, ERK1/2, Akt, MAPK and NF-kB. Curcumin treatment implied as much. The administration of CXCR4 antagonist AMD3100 restrained all changes. These findings were basically consistent with the results from Kim et al. who showed that curcumin induced proliferation of NPCs and NSCs via activation of ERK1/2 and p38 MAPK [14].

Neurogenesis is a developmental process that involves the proliferation, migration and differentiation of neuroblasts and the synaptic integrations of newborn neurons. The contribution of SDF-1/CXCR4 signalling to brain development and neurogene- sis has been widely reported $[9,11,27]$. Itoh et al. showed that chemoattractant SDF-1 migration recruited the overexpression of CXCR4 [11]. Our present study showed the chemotaxis of NSCs in culture to the chemoattractant SDF-1, the co-localization of SDF-1 with CXCR4, and the similar expression trends of SDF-1/CXCR4 complex in NSCs. Our data proved that curcumin promoted the expression of SDF- 1 and CXCR4 and complex of SDF- 1 with CXCR4. The administration of AMD3100 into curcumin-treated NSCs restrained curcumin-induced NSC proliferation, SDF-1/CXCR4 expression and the downstream signalling proteins including phosphorylated ERK, NF-KB, Akt, JNK and MAPK. These results demonstrated that SDF-1/CXCR4 signalling was 

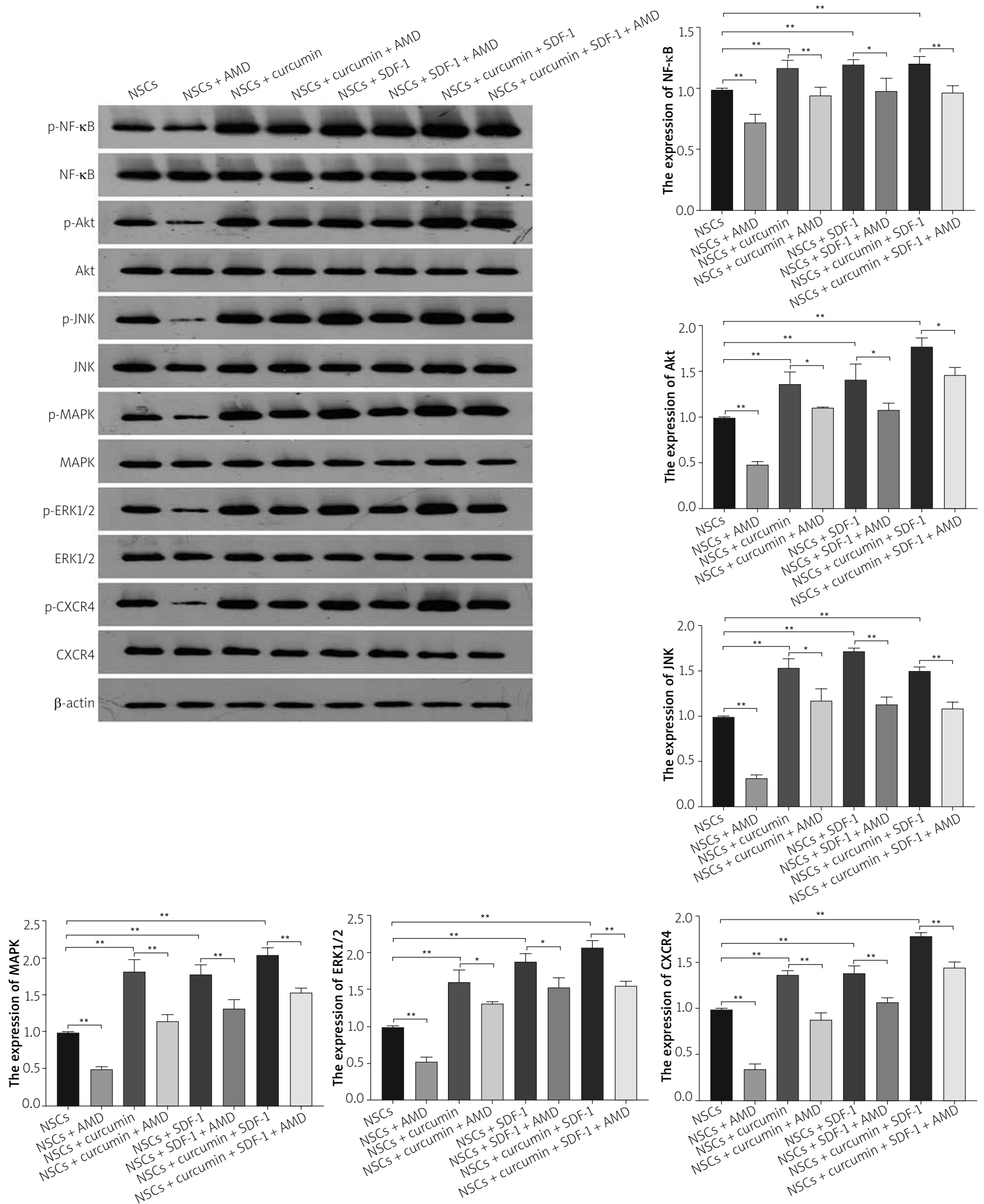

Fig. 5. Western blot analysis of the proliferation-related proteins. 
necessary for curcumin-mediated NSC proliferation and invasion. Our findings were inconsistent with the previously reported fact in tumours that curcumin-mediated anti-tumour effect is related to its association with SDF-1/CXCR4 $[25,26]$.

Previous studies of SDF-1/CXCR4 have proven that it is capable of regulating multiple cells signalling proteins like ERK, Akt, Wnt, MAPK, and JNK $[16,23,31]$. In the in vivo Alzheimer's disease animal experiments performed by Tiwari et al. [28], curcumin nanoparticles increased NSCs proliferation, neurogenesis and neuronal differentiation by activating the $W n t / \beta$-catenin pathway. These pathways play crucial roles in regulating inflammatory [33], promoting migration and survival $[4,10]$, and maintaining differentiation [12] in NSCs. Cui et al. demonstrated that the sulfated polysaccharide isolated from the Stichopus japonicus promoted SDF-1/ CXCR4 axis-induced migration in NSCs via activating the EGF, Akt, ERK, MAPK and NF-kB [4], which was consistent with our findings.

In conclusion, our present study found that SDF-1 and curcumin significantly promoted the NSCs proliferation, invasion, formation of neurospheres, and expression of SDF-1/CXCR4 in NSCS. SDF-1 and curcumin-mediated NSCs proliferation and neurogenesis in culture was mediated by the activation of multiple cells signalling proteins including JNK, ERK1/2, Akt, MAPK and NF-KB. Our findings might provide more and novel information on curcumin-mediated neuroprotection and neurogenesis.

\section{Disclosure}

The authors report no conflict of interest.

\section{References}

1. Attari F, Zahmatkesh M, Aligholi H, Mehr SE, Sharifzadeh M, Gorji A, Mokhtari T, Khaksarian M, Hassanzadeh G. Curcumin as a double-edged sword for stem cells: dose, time and cell type-specific responses to curcumin. Daru 2015; 23: 33.

2. Chen F, Wang H, Xiang X, Yuan J, Chu W, Xue X, Zhu H, Ge H, Zou M, Feng $\mathrm{H}$, Lin J. Curcumin increased the differentiation rate of neurons in neural stem cells via wnt signaling in vitro study. J Surg Res 2014; 192: 298-304.

3. Cheng X, Wang H, Zhang X, Zhao S, Zhou Z, MuX, Zhao C, Teng W. The role of SDF-1/CXCR4/CXCR7 in neuronal regeneration after cerebral ischemia. Front Neurosci 2017; 11: 590.

4. Cui C, Wang P, Cui N, Song S, Liang H, Ji A. Sulfated polysaccharide isolated from the sea cucumber Stichopus japonicas promotes the SDF-1 $\alpha / C X C R 4$ axis-induced NSC migration via the
PI3K/Akt/FOXO3a, ERK/MAPK, and NF-KB signaling pathways. Neurosci Lett 2016; 616: 57-64.

5. Fernandez Cl, Alberti E, Mendoza Y, Martinez L, Collazo J, Rosillo JC, Bauza JY. Motor and cognitive recovery induced by bone marrow stem cells grafted to striatum and hippocampus of impaired aged rats: functional and therapeutic considerations. Ann N Y Acad Sci 2004; 1019: 48-52.

6. Fleenor BS, Sindler AL, Marvi NK, Howell KL, Zigler ML, Yoshizawa M, Seals DR. Curcumin ameliorates arterial dysfunction and oxidative stress with aging. Exp Gerontol 2013; 48: 269-276.

7. Gleichmann M, Gillen C, Czardybon M, Bosse F, Greiner-Petter R, Auer J, Muller HW. Cloning and characterization of SDF-1gamma, a novel SDF-1 chemokine transcript with developmentally regulated expression in the nervous system. Eur J Neurosci 2000; 12: 1857-1866.

8. Hamaguchi T, Ono K, Yamada M. REVIEW: Curcumin and Alzheimer's disease. CNS Neurosci Ther 2010; 16: 285-297.

9. Ho SY, Ling TY, Lin HY, Liou JTJ, Liu FC, Chen IC, Lee SW, Hsu Y, Lai DM, Liou HH. SDF-1/CXCR4 signaling maintains stemness signature in mouse neural stem/progenitor cells. Stem Cells Int 2017; 2017: 2493752.

10. Ishii S, Okada Y, Kadoya T, Matsuzaki Y, Shimazaki T, Okano H. Stromal cell-secreted factors promote the survival of embryonic stem cell-derived early neural stem/progenitor cells via the activation of MAPK and PI3K-Akt pathways. J Neurosci Res 2010; 88: 722-734.

11. Itoh T, Satou T, Ishida H, Nishida S, Tsubaki M, Hashimoto S, Ito $\mathrm{H}$. The relationship between SDF-1alpha/CXCR4 and neural stem cells appearing in damaged area after traumatic brain injury in rats. Neurol Res 2009; 31: 90-102.

12. Jang JY, Hong YJ, Lim J, Choi JS, Choi EH, Kang S, Rhim H. Cold atmospheric plasma (CAP), a novel physicochemical source, induces neural differentiation through cross-talk between the specific RONS cascade and Trk/Ras/ERK signaling pathway. Biomaterials 2018; 156: 258-273.

13. Kakkar V, Muppu SK, Chopra K, Kaur IP. Curcumin loaded solid lipid nanoparticles: An efficient formulation approach for cerebral ischemic reperfusion injury in rats. Eur J Pharm Biopharm 2013; 85: 339-345.

14. Kim SJ, Son TG, Park HR, Park M, Kim MS, Kim HS, Chung HY, Mattson MP, Lee J. Curcumin stimulates proliferation of embryonic neural progenitor cells and neurogenesis in the adult hippocampus. J Biol Chem 2008; 283: 14497-14505.

15. Lendahl U, Zimmerman LB, McKay RD. CNS stem cells express a new class of intermediate filament protein. Cell 1990; 60: 585-595.

16. Liao YX, Fu ZZ, Zhou CH, Shan LC, Wang ZY, Yin F, Zheng LP, Hua YQ, Cai ZD. AMD3100 reduces CXCR4-mediated survival and metastasis of osteosarcoma by inhibiting JNK and Akt, but not p38 or Erk1/2, pathways in in vitro and mouse experiments. Oncol Rep 2015; 34: 33-42.

17. Liu L, Zhang W, Wang L, Li Y, Tan B, Lu X, Deng Y, Zhang Y, Guo X, $\mathrm{Mu}$ J, Yu G. Curcumin prevents cerebral ischemia reperfusion injury via increase of mitochondrial biogenesis. Neurochem Res 2014; 39: 1322-1331.

18. Liu X, Mao J, Han C, Peng S, Li C, Jin T, Fan C, Shan Z, Teng W. CXCR4 antagonist AMD3100 ameliorates thyroid damage in 
autoimmune thyroiditis in NOD.H2h(4) mice. Mol Med Rep 2016; 13: 3604-3612.

19. Ma X, Liu J, Wang C, Zhou J, He Z, Lin H. Low-dose curcumin stimulates proliferation of rat embryonic neural stem cells through glucocorticoid receptor and STAT3. CNS Neurosci Ther 2018; 24: 940-946.

20. Mishra S, Palanivelu K. The effect of curcumin (turmeric) on Alzheimer's disease: An overview. Ann Indian Acad Neurol 2008; 11: 13-19.

21. Peled A, Grabovsky V, Habler L, Sandbank J, Arenzana-Seisdedos F, Petit I, Ben-Hur H, Lapidot T, Alon R. The chemokine SDF-1 stimulates integrin-mediated arrest of CD34(+) cells on vascular endothelium under shear flow. J Clin Invest 1999; 104: 1199-1211.

22. Rabenstein M, Hucklenbroich J, Willuweit A, Ladwig A, Fink G, Schroeter M, Langen K, Rueger MA. Osteopontin mediates survival, proliferation and migration of neural stem cells through the chemokine receptor CXCR4. Stem Cell Res Ther 2015; 6: 99.

23. Ryu C, Park S, Kim S, Lim J, Jeong C, Jun J, Oh J, Park S, Oh W, Jeun SS. Migration of human umbilical cord blood mesenchymal stem cells mediated by stromal cell-derived factor-1/ CXCR4 axis via Akt, ERK, and p38 signal transduction pathways. Biochem Biophys Res Commun 2010; 398: 105-110.

24. Sikora E, Scapagnini G, Barbagallo M. Curcumin, inflammation, ageing and age-related diseases. Immun Ageing 2010; 7: 1.

25. Sirohi VK, Popli P, Sankhwar P, Kaushal JB, Gupta K, Manohar M, Dwivedi A. Curcumin exhibits anti-tumor effect and attenuates cellular migration via Slit-2 mediated down-regulation of SDF-1 and CXCR4 in endometrial adenocarcinoma cells. J Nutr Biochem 2017; 44: 60-70.

26. Skommer J, Wlodkowic D, Pelkonen J. Gene-expression profiling during curcumin-induced apoptosis reveals downregulation of CXCR4. Exp Hematol 2007; 35: 84-95.

27. StewartAN, Kendziorski G, DeakZM, Brown DJ, Fini MN, Copely KL, Rossignol J, Dunbar GL. Co-transplantation of mesenchymal and neural stem cells and overexpressing stromal-derived factor-1 for treating spinal cord injury. Brain Res 2017; 1672: 91-105.

28. Tiwari SK, Agarwal S, Seth B, Yadav A, Nair S, Bhatnagar P, Karmakar M, Kumari M, Chauhan LKS, Patel DK, Srivastava V, Singh D, Gupta SK, Tripathi A, Chaturvedi RK, Gupta KC. Correction to curcumin-loaded nanoparticles potently induce adult neurogenesis and reverse cognitive deficits in Alzheimer's disease model via canonical Wnt/beta-catenin pathway. ACS Nano 2019; 13: 7355.

29. Wang Q, Sun AY, Simonyi A, Jensen MD, Shelat PB, Rottinghaus GE, MacDonald RS, Miller DK, Lubahn DE, Weisman GA, Sun GY. Neuroprotective mechanisms of curcumin against cerebral ischemia-induced neuronal apoptosis and behavioral deficits. J Neurosci Res 2005; 82: 138-148.

30. Yan R, Xu H, Fu X. Salidroside protects hypoxia-induced injury by up-regulation of miR-210 in rat neural stem cells. Biomed Pharmacother 2018; 103: 1490-1497.

31. Yang P, Wang G, Huo H, Li Q, Zhao Y, Liu Y. SDF-1/CXCR4 signaling up-regulates survivin to regulate human sacral chondrosarcoma cell cycle and epithelial-mesenchymal transition via ERK and PI3K/AKT pathway. Med Oncol 2015; 32: 377.
32. Yang Z, Wang KKW. Glial fibrillary acidic protein: from intermediate filament assembly and gliosis to neurobiomarker. Trends Neurosci 2015; 38: 364-374.

33. Zhu W, Li J, Liu Y, Xie K, Wang L, Fang J. Mesencephalic astrocyte-derived neurotrophic factor attenuates inflammatory responses in lipopolysaccharide-induced neural stem cells by regulating NF-KB and phosphorylation of p38-MAPKs pathways. Immunopharmacol Immunotoxicol 2016; 38: 205-213. 